\title{
UCLA
}

Mester

Title

A Papá

Permalink

https://escholarship.org/uc/item/6013s3k4

Journal

Mester, 18(1)

Author

Cesareo, Mario

Publication Date

1989

DOI

10.5070/M3181014019

Copyright Information

Copyright 1989 by the author(s). All rights reserved unless otherwise indicated. Contact the author(s) for any necessary permissions. Learn more at https://escholarship.org/terms

Peer reviewed 
Mester, Vol. xviii, No. I (Spring, 1989)

\section{La imagen de la estatua de sal: síntesis y clave en el pensamiento poético de Olga Orozco}

"nada hay oculto si no es para que sea manifestado" (Marcos IV 22)

(Los verdaderos alquimistas) se expresan siempre a través de imágenes, figuras y metáforas, para que puedan entenderlos sólo las almas sabias, santas e iluminadas por el saber. Sin embargo en sus obras han trazado cierto camino y determinada regla, de manera que el sabio pueda entender, $y$, finalmente, lograr, tras algunas pruebas, todo cuanto ellos describen de manera encubierta. (Burckhardt 30-1)

Esta afirmación de Sinesio del siglo IV de nuestra era, referida al código hermético de los alquimistas, se podría aplicar por carácter analógico al lenguaje de los poetas. Y si se sustituye en el párrafo citado la palabra "sabio" por la idea de "intérprete", se dará con el "camino" necesario para comprender y transitar las "reglas ocultas" subyacentes a toda obra poética.

Nos proponemos en este trabajo rastrear el proceso de transformación "alquímica" que sufre la imagen de la estatua de sal en el itinerario poético de Olga Orozco. En efecto, es notable comprobar la recurrencia con que aparece esta figura en su poesía. ' Se trata sin duda de una imagen arquetípica predominante en el espíritu de esta autora, un modo de condensación de sentidos donde convergen los diversos motivos que componen el espectro temático de su pensamiento poético. Siguiendo al antropólogo francés Gilbert Durand, sugerimos que se trata de la "figura simbólica" —es decir, la representación icónica de un sentido oculto- que suscita una constelación de figuras poéticas configurativas de su obra. ${ }^{2}$ 
Según este autor, del símbolo emana un número de manifestaciones expresivas que repiten y aumentan su alcance semántico para perfeccionar así su comprensión. ${ }^{3}$ Del mismo modo, es posible descubrir en la obra de Olga Orozco una redundancia semántica, una acumulación instauradora de sentido, cuyas imágenes o figuras representativas conforman la "estructura figurativa" de su poesía. ${ }^{4}$

Siguiendo a Durand, entendemos por "estructura" la interacción, el flexible dinamismo de un conjunto de "fuerzas" orientadas por y hacia un sentido, cuyo modelo nuclear es la relación equívoca - pero, por esto mismo fecunda- entre el símbolo y lo simbolizado. ${ }^{5}$ El hilo conductor de estas fuerzas estructurantes estará dado entonces por el "régimen de la imagen", "que señala los motivos simbólicos y que indica las tendencias imaginarias subjetivas, el 'carácter' imaginal del autor" (Durand, Figures 123). Por medio de estas representaciones se sintetiza con gran economía el contenido del subconsciente poético.

El objetivo de este estudio será pues, atender a las resonancias poéticas que emite esta imagen y captar sus correspondencias simbólicas en una disciplina cosmológico-espiritual, la alquimia. Para ello se tendrá siempre presente el método de trabajo de Gaston Bachelard - la fenomenología de la ensoñación poética- que enseña: "La imagen sólo puede ser estudiada por medio de la imagen, soñando imágenes, tal como se componen en la ensoñación'. (Durand, Imaginación 78)

Toda obra verdaderamente artística sufre un proceso análogo al de la "Gran Obra" de los alquimistas, en la que se cumple la transmutación de los metales en el codiciado oro. Del mismo modo que el alquimista intenta alcanzar su perfección interior — simbolizada en su actividad por la obtención del preciado metal-, asi también todo artista, al plasmar su mundo de fantasmas interiores, experimenta un proceso de individuación que le permite finalmente ver reflejada su propia imagen en el espejo de su obra. Como bien dice Roger Bastide parafraseando a Mallarmé: “La obra de arte es la creación del espejo donde Narciso descubrirá su desnudez". ' (Durand, Figures 275). Pensamos que la imagen que le devuelve este espejo a la poeta Olga Orozco es justamente la de la estatua de sal.

Así como todas las cosas proceden del Uno y de la meditación del Unico, también todas las cosas nacen de este Uno mediante conjugación. (Burckhardt 237)

Este es el segundo apotegma de la Tabla Esmeraldina, presunta revelación de Hermes Trimegisto, que sintetiza el significado del proceso de la 
obra alquímica. Se podría resumir con las palabras citadas la preocupación última de Olga Orozco, expresada en su obra ${ }^{7}$ como una constante nostalgia por la Unidad perdida, y una angustiosa consciencia de la ruptura que implica la conjugación del Uno para "hacer nacer" las cosas de este mundo.

Es bien notoria la dualidad que vive esta "exiliada del Reino" al experimentar lo mundano como si fuera la "herida" de un "paraíso roto" (PSA 102). Su actitud es la de quien se siente desgarrado por fuerzas antagónicas difíciles —o quizás imposibles - de conciliar en esta existencia terrena. En su poesía, la materia vive en lucha constante con el espíritu, el cuerpo con el alma, las tinieblas con la luz, la vida con la muerte, la vivencia del rapto creador con los precarios vocablos que componen sus poemas. Esa escisión se hace a veces tan patente, que aún dentro de su propia persona, experimenta un fuerte sentimiento de otredad, un extrañamiento de sí misma debido a la duplicidad de su sustancia. Indudablemente, esta actitud tiene afinidades con la doctrina gnóstica, que marca una separación tajante entre el bien, referido al espíritu, y el mal, referido a la materia.

En su poesía, una posible superación de esta dualidad la da el amor, que brinda una efímera plenitud a esta desgarrada existencia. Pero este sentimiento es siempre "despiadado" (OP 77), es experimentado como ausencia, relacionado las más de las veces al "olvido", y no a una presencia fecunda. De este modo la división permanece vigente.

El poema "La caída", del libro Los juegos peligrosos resume de manera ejemplar este motivo. Se trata de una mirada introspectiva de la autora, su persona y el "doble"' representados por dos estatuas. Fue necesario detener el fluir existencial en esta forma estática para captar más patentemente la inmutabilidad de la esencia. Si nos atenemos a la equilibrada simetría de la composición, se verá que la “estatua del azul” está ubicada entre los versos que corresponden a la invocación del alma. Dice en la parte central del poema, manteniendo una postura meramente apelativa ante estas dos estatuas que se enfrentan como si fueran Narciso contemplando su propia imagen frente a las claras aguas de un estanque:

(¡Oh alma!, ¿adónde vas?,

¿adónde vas con las tinieblas y la luz como dos alas abiertas para el vuelo?)

Estatua del azul: yo no puedo volver.

Me exiliaste de ti para que consumiera tu lado tenebroso.

y luego:

(¿Oh sangre! ¿adónde vas?

¿adónde vas como el doble de Dios y con la espada hundida en tu costado?) 
Bella estatua de sal: tú no puedes llegar.

Te desterraste en mí para escarbarme con uñas y con dientes.

Aparte de su cuidada estructura formal, que manifiesta una rigurosa simetría, es importante observar el mismo recurso en el simbolismo de las imágenes. En efecto, el color "azul”' está referido al plano espiritual, mientras que la "sangre", como fluido esencial de nuestro organismo, es una referencia metonímica del "cuerpo". La "estatua del azul”, entonces, es no sólo el alma que informa al cuerpo, sino también su molde celeste ("Estatua del azul, deshabitada," aclara en el verso inicial) que permanece en las entrañas del Uno, a la espera del regreso del alma que se "exilió de sí" para encarnarse en un cuerpo terrestre. Por su lado, la "bella estatua de sal" alude claramente al cuerpo, pero también a la unión de cuerpo y alma. Esta ambigüedad puede ser homologada a la particular composición de la sal: es un cuerpo sólido, como la piedra, pero, al mismo tiempo, tiene la capacidad de disolverse con facilidad. De igual manera, posee una cierta opacidad, como toda materia, sin embargo, por su virtual transparencia, se asemeja al cristal, que generalmente simboliza al alma.

El significado de esta imagen está casi siempre referido a la bíblica mujer de Lot; así aludirá generalmente al castigo impuesto por las rebeldías cometidas. Este, en su sentido alegórico. Pero, antes de seguir profundizando en el simbolismo de esta imagen, debemos retrotraernos a su génesis, a sus primeras expresiones poéticas y rastrear la gestación "material" de esta figura que acabamos de contemplar ya cristalizada.

III

Las imágenes poéticas tienen, también ellas, una materia (. . . ) Para que una meditación se prosiga con bastante constancia como para dar una obra escrita, como para que no sea tan sólo la fiesta de una hora fugitiva, debe hallar su materia, es necesario que el elemento material le dé su propia sustancia, su propia regla, su poética especfífica. (10-1)

Afirma Gastón Bachelard en su estudio El agua y los sueños acerca de la imaginación material. Y agrega más adelante: "la materia ayuda a determinar el desttino humano" (11).

Si tomamos a las "lágrimas" como signo emblemático del destino desdichado que se trasluce en la obra de Olga Orozco, podremos asegurar por analogía "material" que su poética específica es la acuática. En efecto, la materia que privilegia la imaginación poetizante de esta autora heracliteana siempre atenta al constante fluir de la vida que va a dar irremisiblemente en el "mar" de la muerte, es, a no dudarlo, el agua. Pero el agua se pre- 
senta en su poesía como la sustancia innominada, se la reconoce más por su ausencia que por su presencia. Un ejemplo de esta idea la da la propia poeta al referirse a su infancia, el momento más cercano al Paraíso:

Mi infancia comenzó en Toay, en La Pampa, y te digo que comenzó porque no ha terminado. Siguió creciendo conmigo y ha estado siempre latente, en todas mis edades, con su carga de terrores, de asombros y de misterios. Si no estuviera dentro de mí como un carozo o como un lugar, te diría que es una casa prodigiosa que anda entre los médanos y los cardos rusos, llevada por el viento, en medio de una planicie que alguna vez fue el mar y donde cada huesecito toma bajo la luz un relieve insensato. $(P S A 273)^{8}$

Su infancia, entonces, es una "casa prodigiosa" ubicada en una planicie que "alguna vez fue el mar”. Creemos que está aquí el núcleo onírico de su creación literaria. Ubiquémonos en ese pueblecito pampeano que vive la nostalgia del mar que ya no está, pero que se manifiesta por sus sedimentos: los "médanos", los "huesecitos", en fin los "salitrales". Y así, por proceso metafórico se llega al gran tema: la infancia (la vida) está ubicada sobre un salitral, mejor es un salitral. Por esto se conserva la nostalgia del mar, del agua maternal que remite a la calidez de la vida en el seno materno, y más lejos aún, a ese "caos-cósmico" - si se me permite la contradicción - de la vida anterior a la vida.

El mar, entonces, representa no sólo a su madre perdida tempranamente, sino que también es símbolo de la Unidad, de la plenitud. Lo paradójico es que el mar no es un elemento tan mentado en su obra como la sal, el sedimento que corroe y trae sufrimiento, pero que sin embargo, también purifica. He aquí un dato más acerca de la ambigüedad de esta sustancia.

Pero, volviendo al agua, es preciso recordar que esta materia, por su ductilidad, puede transformar su estado. de este modo, de líquido, pasa por congelación al estado sólido, y por evaporación, al aire. Este cambio de estados marcará las distintas etapas del proceso alquímico que atravesará la imaginación material de esta autora. Los dos primeros pasos de este proceso - el de disolución y solidificación - llamados en alquimia solve et coagula, se darán en su obra con reiterada intermitencia. Acompañemos el procesamiento de estas dos sustancias, el agua y la sal, que en el illo tempore imaginante de Olga Orozco están fundidas en el salobridad marina.

En su primer libro, Desde lejos, en el que está presente el paisaje de su pueblo natal, el agua ya ha retrocedido para dejar tan sólo el rastro de sus sedimentos: la arena, los huesos, las piedras, el polvo, la ceniza, la sal. Encontramos la clave simbólica de estos "restos" en un libro publicado treinta y tres años más tarde: Mutaciones de la realidad. Efectivamente, en el poema "La imaginación abre sus vertiginosas trampas", por medio 
de una simbología marítima, se hace referencia a estos "despojos" que han quedado como "cenizas" del "oro" de la plenitud primordial:

- itanta alquimia al revés!-

y caer como cae una llovizna de oro transmutada en cenizas y en adiós

en estas habitaciones donde tan sólo bajan las mareas

arrastrando monedas desgastadas,

objetos que perdieron definitivamente su nombre y su sentido despojos imprecisos atados con las guirnaldas rotas de la fiesta - todo lo que ya es inventario de polvo, reclamo de naufragio allá, en las canteras vertiginosas de la resurreción-

(MR 64)

Serán estas "cenizas", pues, la sustancia "desintegrada" que compondrá la aridez de la vida. Paulatinamente, ésta se irá "integrando" en sucesivas corporizaciones que representarán arquetípicamente la esencia inmutable de la poeta. Enumerándolas de manera progresiva: primero, el "cuerpo transparente", luego las "dóciles máscaras", hasta llegar finalmente a la "estatua":

Nada fueron en ella las sombrías tormentas,

el tiempo, la distancia, el triste decaer de las cosas terrestres

que solamente dejan en nosotros derrumbe y soledad.

$(O P 25)$

dice en "Flores para una estatua", enfatizando claramente el contraste entre la perdurabilidad de la esencia y la desintegración a la que está sometido el flujo existencial de los individuos.

Pero aparece además en su primer libro un tercer elemento que participará luego del significado de la imagen que nos ocupa. Se trata de la consecuencia que acarrea la imposible saciedad experimentada por la poeta en este mundo de residuos, en el que estamos "mordidos por una sed que nada colma nunca" (OP 48). Es esta "sed" del agua primordial el castigo impuesto por nuestra condición humana, la culpa que debemos purgar con obediencia, acatando el mandato divino, la "ley": "no es preciso volver la vencida cabeza en despedida" (OP 28), aconseja para el final del viaje terreno. Esta referencia mítica a la obediencia indicada por la divinidad, tanto a la mujer de Lot como a Orfeo, abre el sentido de esta imagen a su nivel alegórico: el desacato se paga con la conversión en estatua de sal. Estatua que fijará en la eternidad de un instante de desesperanza los sufrimientos padecidos durante toda una vida. Se mantendrá desde entonces la autora en un delicado equilibrio entre la sumisión y la rebeldía.

La perfecta integración de esta figura simbólica se dará recién en su tercer libro, Los juegos peligrosos. Es en el poema "La caída" — citado ante- 
riormente- donde aparece por primera vez la mención clara a la "estatua de sal" . La identificación de la poeta con esta imagen es evidente: "déjame contemplar en la nostalgia de esas vivas estatuas que miran hacia atrás" ( $O P 88)$; anhelo que traduce su remordimiento por alguna desobediencia "hacia lo alto". Es importante señalar que estas estatuas, en la imaginación creadora de Olga Orozco, están "vivas”, es decir, poseen un dinamismo interno que transforma su composición material-simbólica con el paso del tiempo. En efecto, recordemos que en el origen se hallaba disuelta en el agua; más tarde pasa a la solidez desintegrada, condensándose de a poco en una forma humana. A continuanción veremos cómo esta estatua "cobra vida" y anuncia como en una profecía, su sublimación en un cuerpo etéreo.

Pero es preciso consignar primero la conciliación de opuestos que brinda la cristalización de esta rica imagen. En ella se superan las dualidades que tanto desgarraban a esta autora, en una suerte de "bodas químicas" entre la sustancia (la sal) y la esencia (la estatua). Así, la estatua representará al Hombre, que, como "imagen del Universo", es el mediador entre el mundo espiritual y el mundo físico, y que por su doble naturaleza, participa de ambos. La sal, por su lado, es para la alquimia, "la ceniza que queda y que sirve para retener el espíritu volátil”' (Burckhardt 173). De este modo, por medio de los sufrimientos, purifica al cuerpo y lo convierte en el "punto de apoyo y sujeción de un estado más elevado del espíritu", (Burckhardt 173). El alquimista Basilio Valentino dice al respecto:

Toda carne que ha nacido de la tierra será destuida y vuelta a la tierra, y volverá a ser tierra, como tierra había sido. Entonces, la sal terrena provocará un nuevo nacimiento, mediante el hálito de la vida celestial. Y dondequiera que en un principio no hubiese estado la tierra, no puede haber un renacimiento según nuestra obra. Porque la tierra es el bálsamo de la Naturaleza y la sal de aquéllos que buscan el conocimiento de todas las cosas. (Burckhardt 224)

Búsqueda a la que sin duda se aboca Olga Orozco hasta el punto de franquear el umbral de lo que le está permitido al espíritu humano, intuyendo, sin embargo, por medio de esta afanosa pesquisa, que la verdadera plenitud se alcanza a través de las nupcias simbólicas:

Entre las ceremonias del amor

ninguna es comparable al matrimonio del sol y de la luna. (OP 94)

referencia evidente a la boda alquímica que logra recobrar la naturaleza completa de nuestra especie, superando la dualidad entre la materia y el espíritu, entre lo humano y lo divino, haciendo accesible de este modo, al Dios recóndito oculto en todo corazón.

$\mathrm{Al}$ alcanzar así "ese lugar de pequeñas alianzas como chispas" ( $M R$ 19) que Olga Orozco reclamaba como único don, accedemos al último paso 
de este proceso, el de la “alquimia volátil que evapora las duras condensaciones de los años" (OP 155). Simultáneamente, se ha ido generando una nueva aptitud en la poeta, que se manifiesta a través de una identificación con la "esfinge", la "sibila", la "vidente", hasta coincidir este poder profético con la imagen de la estatua de sal.

Si nos remitimos a los últimos versos de su poema "Presentimientos en traje de ritual", hallaremos la integración de los distintos motivos simbólicos que hemos venido analizando. Con una imagen de lúcida belleza, comprendemos que la estatua de sal — ahora absolutamente identificada con el sujeto lírico - se ha convertido en un cuerpo sutil, al margen del tiempo humano, y que comparte la condición visionaria de quien está inmerso en la eternidad divina:

Entonces la insoluble sustancia que no soy,

esa marea a tientas que sube cuando bajan los tigres en el alba,

tapiza la pared,

me tapia las ventanas,

destapa los disfraces del verdugo que me mata mejor.

Me arrancan de raíz.

Me embalsaman en estatua de sal a las puertas del tiempo.

Soy la momia translúcida de ayer convertida en oráculo. (MR 16)

Y ahora sí, ya celebradas las "agonias litúrgicas como ceremonias de adaptación al purgatorio"' ( $M R 86)$, estarán preparados su "carne intangible" y sus "disueltos pies" ( $M R 30$ ), para acudir con sus "grandes transparencias" (MR 155) a la "fiesta de la resurrección"' (MR 9).

Se completa de este modo el proceso de individuación de la autora, la conquista de su ser profundo a través de la equilibración brindada por su actividad poetizante. Se logró así superar simbólicamente la dualidad, mediante la representación de una unión misteriosa que condujo el trayecto hasta la adquisición de la plenitud sublimadora.

Silvia Pellarolo

University of California, Los Angeles

\section{NOTAS}

1. Marcaba en un trabajo anterior la recurrencia con que aparece esta figura en la poesia orozquiana: La poesía de Olga Orozco: un jardín tras las tinieblas, artículo que forma parte del volumen colectivo Defensa del poela, Buenos Aires, Corregidor (en prensa)

2. 'Las cosas sólo existen por medio de la 'figura' que les da el pensamiento objetivante; son eminentemente 'símbolos', ya que sólo conservan la coherencia de la percepción, de la conceptualización, del juicio o del razonamiento mediante el sentido que se les impregna". (Durand, Imaginación 70) 
3. "el imperialismo del significante, que al repetirse llega a integrar en una sola figura las cualidades más contradictorias, así como el imperialismo del significado, que llega a inundar todo el universo sensible para manifestarse sin dejar de repetir el acto 'epifánico', poseen el carácter común de la redundancia. Mediante este poder de repetir, el símbolo satisface de manera indefinida su inadecuación fundamental. Pero esta repetición no es tautológica, sino perfeccionante, merced a aproximaciones acumuladas. A este respecto, es comparable a una espiral, o mejor dicho a una solenoide, que en cada repetición circunscribe más su enfoque, su centro. No es que un solo símbolo no sea tan significativo como todos los demás, sino que el conjunto de todos los símbolos relativos a un tema los esclarece entre sí, les agrega una 'potencia' simbólica suplementaria". (Durand, Imaginación 17)

4. “(. . . ) dans l'aventure de l'interprétation, de l'équivocité, où commence le délire répréhensible? On oublie trop souvent -et un certain pédantisme structural n'a pas peu contribué à cet oubli! - que l'essentiel pour un poème est de plaire et pour un commentaire d'amplifier s'il se peut ce plaisir. 11 faudrait se demander toujours avant l'exégèse 'à quoi sert un poème?, et bien voir par là, s'il ne sert que la poésie, qu'il ne 'sert à rien' (comme l'a dit Kant avant Th. Gautier!). Il n'a surtout pas de 'sens propre', pas d'inflexible univocité comme voudraient nous le faire croire les prestigieux mécaniciens du formalisme linguistique. 11 n'est que figure qui - Bachelard l'a bien dit-suscite des figures. Et la structure qu'on peut lui trouver est bien finalement une 'structure figurative'." (Durand, Figures 111)

(Es importante aclarar que Durand emplea los términos "imagen" y "figura" indistintamente. Las traducciones en el cuerpo del trabajo son nuestras).

5. "En effet de même que la structure est un rapport oủ les éléments ne sont pas 'arbitraires' parce qu'ils ne sont pas de signes saussuriens mais des forces, des 'res dynamicae' orientées, donc ayant un sens, le symbole est le vecteur sémantique de base dans lequel le symbolisant figure le symbolisé. Et le figure adéquatement, c'est à dire de tout 'patron' où les formes résultent et expriment des forces et des matières (donc au moins un couple de forces antagonistes). Le modèle structural que je donne d'un phénomène est sa figure opératoire, son symbole par rapport au symbolisé - aussi indicible que tout symbolisé-que constitue l'intégrité et l'individualité (l'unicité) du phénomène." (Durand, Figures 9l)

6. La paráfrasis de Mallarmé: “O miroir!/Eau froide par l'ennui dans ton cadre gelée/ Que de fois et pendant des heures, désolée/Des songes et chercant mes souvenirs qui sont/ Comme des feuilles sous la glace au trou profond,/Je m'apparus en toi comme une ombre lointaine,/Mais, horreur! dessoirs, dans ta sévère fontaine, $/ \mathrm{J}$ 'ai de mon rêve épars connu la nudité!' Stépahane Mallarmé. Hérodiade, citado por Bachelard, El agua 41.

7. Obra publicada de Olga Orozco:

DL: Desde lejos. Buenos Aires, Losada, 1946

LM: Las muertes. Buenos Aires, Losada, 1951

JP: $\quad$ Los juegos peligrosos. Buenos Aires, Losada, 1962

OOS: La oscuridad es otro sol. Buenos Aires, Losada, 1967

MS: $\quad$ Museo salvaje. Buenos Aires, Losada, 1974

VP: Veintinueve poemas. Caracas, Monte Avila, 1975

CB: Cantos a Berenice. Buenos Aires, Sudamericana, 1977

OP: Obra poética. Buenos Aires, Corregidor, 1979/85

MR: Mutaciones de la realidad. Buenos Aires, Sudamericana, 1979

ND: $\quad$ La noche a la deriva. México, FCE, , 1984

PSA: Páginas seleccionadas por la autora. Buenos Aires, Celtia, 1984

RC: En el revés del cielo. Buenos Aires, Sudamericana, 1987

8. Entrevista de Alicia Dujovne Ortiz para "La Opinión" (22-1-78) (PSA 273)

\section{OBRAS CONSULTADAS}

Bachelard, Gastón. El agua y los sueños. México, F.C.E., 1978

Burckhardt, Titus. Alquimia: significado e imagen del mundo. Barcelona, Plaza y Janés, 1976

Durand, Gilbert. La imaginación simbólica. Buenos Aires, Amorrortu, 1971

- Figures mythiques et visages de l'oeuvre. Paris, Berg International, 1979

Chetwynd, Tom. A Dictionary of Symbols. London, Granada, 1982 